OPEN ACCESS

Edited by: Ricardo Scott,

University of Alicante, Spain

Reviewed by:

Laura Sokal,

University of Winnipeg, Canada Irena Smetackova,

Charles University, Czechia

*Correspondence: Marie Weißenfels marie.weissenfels@uni-saarland.de

Specialty section:

This article was submitted to Educational Psychology, a section of the journal Frontiers in Education

Received: 06 July 2021 Accepted: 13 December 2021 Published: 05 January 2022

Citation:

Weißenfels M, Klopp E and Perels F (2022) Changes in Teacher Burnout and Self-Efficacy During the COVID-19

Pandemic: Interrelations and eLearning Variables Related to Change.

Front. Educ. 6:736992.

doi: 10.3389/feduc.2021.736992

\section{Changes in Teacher Burnout and Self-Efficacy During the COVID-19 Pandemic: Interrelations and e-Learning Variables Related to Change}

\author{
Marie Weißenfels *, Eric Klopp and Franziska Perels \\ Department of Educational Sciences, Saarland University, Saarbrücken, Germany
}

Although the reciprocal relationship of teacher burnout and teacher self-efficacy (TSE) is well documented, the literature still lacks studies investigating their (latent) changes and interrelations of change over time. By applying a latent change regression model in our study, we aimed to contribute to this research gap by examining changes in burnout and their relations to changes in TSE during the COVID-19 pandemic - a very challenging time for teachers. As the implementation of digital learning material played a major role during the pandemic, we were also interested if attitudes and self-efficacy toward e-Learning were related to changes in burnout and TSE. Our sample consisted of 92 German inservice teachers who completed a questionnaire twice during the 2019-2020 school year. Our main findings are that the burnout components depersonalization and lack of accomplishment significantly increased from the pre- to post-COVID-19 outbreak, whereas emotional exhaustion did not. Changes in burnout were negatively correlated to changes in TSE, but we found little evidence for relations of change in burnout and TSE with variables concerning e-Learning. Our findings indicate that the challenge was not the work overload but rather a lack of resources. Implications for research and practice are discussed.

Keywords: burnout, self-efficacy, latent changes, COVID-19, in-service teachers

\section{INTRODUCTION}

There is little doubt that teaching is a burdened profession (for a review, see García-Carmona et al., 2019), and in 2020, teachers faced a completely new challenge: the COVID-19 pandemic, which was described as "the greatest challenge that we have faced since World War II" (Saha and Dutta, 2020). Health-care workers were at high risk for mental illness during the outbreak (Huang and Zhao, 2020), but the psychological impact of COVID-19 on the general population and teachers, in particular, is very serious as well (e.g., Allen et al., 2020; Sokal et al., 2020a; Sokal et al., 2020b; Hansen et al., 2020; Kim et al., 2021). In light of social distancing, 194 countries closed schools to contain the pandemic (UNESCO, 2020). Teachers taught remotely, providing online materials for their students and supporting them during a frightening time from a distance. When schools gradually reopened, teachers were exposed to a particularly high risk of infection. 
The pandemic's consequences on teachers' mental health remain largely unknown, very few studies have aimed at discovering effects on teachers during the pandemic (see e.g., Allen et al., 2020; Hansen et al., 2020; Sokal et al., 2020a; Sokal et al., 2020b; Kim et al., 2021). The present study therefore focuses on teacher burnout as an indicator of teachers' mental health and teacher self-efficacy (TSE) as a highly relevant resource against burnout (Bakker et al., 2005) and will investigate their changes during the pandemic. It further analyzes the role of self-efficacy and attitudes toward e-Learning in these changes, as these are potentially relevant variables in times of distance learning.

\section{THEORETICAL FRAMEWORK}

\section{Teacher Burnout}

High demands on teachers (e.g., the challenging situation of school closures due to the COVID-19 pandemic) can affect teachers' mental health and lead to job burnout (Demerouti et al., 2001). "Job burnout is a psychological syndrome that involves a prolonged response to stressors in the workplace" (Maslach, 2003, p. 189). Research on burnout syndrome began in the mid-1970s in the United States and was primarily based on experiences of people working in human services (e.g., Freudenberger, 1975). Considering the interpersonal aspect of burnout syndrome, the work context, it is distinct from clinical syndromes like depression, which in contrast, affect every domain of a persons' life (Maslach et al., 2001). With the teaching profession's highly demanding nature, researchers have conducted much research on teacher burnout in recent years (for a review, see García-Carmona et al., 2019).

Maslach's (1982) multidimensional theory of burnout is still predominant, with burnout's core dimensions described as "overwhelming exhaustion, feelings of cynicism and detachment from the job, and a sense of ineffectiveness and lack of accomplishment" (Maslach, 2003, p.190). Emotional exhaustion is the key dimension of burnout and is characterized by an actual stress reaction, which is highly related to work overload. Perhaps, as a way to cope with this workload, people distance themselves mentally-either from their work in general (cynicism) or from work relationships (depersonalization). The former is a broad conceptualization of mental distancing and applicable for many professions, however it lacks the interpersonal aspect (e.g., Simbula and Guglielmi, 2010). Thus, depersonalization and cynicism are correlated but clearly distinct constructs (e.g., (Larsen et al., 2017) ). In the teaching profession, mental distancing from students (depersonalization) seems to play a more important role which is why it is assessed in the MBI-ES solely rather than cynicism (Maslach et al., 1996). The third component, lack of accomplishment (e.g., a self-evaluated incompetence), can develop either as a consequence of or simultaneously with the other dimensions (Maslach, 2003). In contrast to emotional exhaustion and depersonalization, lack of accomplishment is most clearly influenced by a lack of relevant resources (Maslach, 2003; see also Alarcon (2011) for meta-analysis).
Demerouti et al. (2001) provided the job demands-resources model of burnout (JD-R model) to explain the development of burnout. The researchers divided working conditions into two main categories: job resources and job demands.

"Job demands refer to those physical, social, or organizational aspects of the job that require sustained physical or mental effort and are therefore associated with certain physiological and psychological costs (e.g., exhaustion), [whereas] job resources refer to those physical, psychological, social, or organizational aspects of the job that may do any of the following: 1) be functional in achieving work goals, 2) reduce job demands at the associated physiological and psychological costs, 3) stimulate personal growth and development"(Demerouti et al., 2001, p. 501).

According to the JD-R model of burnout, burnout development follows two processes: First, high job demands result in increased emotional exhaustion. Second, emotional exhaustion is intensified by a lack of resources, resulting in burnout. Specifically, the workload level was often found to strongly predict the emotional exhaustion component (Pogere et al., 2019).

Research has shown that job burnout is negatively related to work engagement (Hakanen et al., 2006), job satisfaction (Skaalvik and Skaalvik, 2017), and subjective health (Hakanen et al., 2006). However, burnout is positively related to the intention to quit the teaching profession (Skaalvik and Skaalvik, 2011), which underlines burnout's role as a mentalhealth indicator and the need to examine job burnout predictors for the well-being of educational systems.

In light of the JD-R model of burnout, TSE can be seen as an internal resource and is, therefore, investigated in this study.

\section{Teacher Self-Efficacy}

Self-efficacy's construct has been strongly influenced by Albert Bandura's social cognitive theory, in which he described people as self-organizing, proactive, self-regulating, and self-reflecting agents of their life circumstances (Bandura, 2001). He defined self-efficacy as "people's judgement of their capabilities to organize and execute courses of action required to attain designated types of performances" (Bandura, 1986, p. 391). Accordingly, TSE is 'the teacher's belief in his or her capability to organize and execute courses of action required to successfully accomplish a specific teaching task in a particular context' (Tschannen-Moran et al., 1998, p. 233).

According to Bandura (1977), one can derive self-efficacy beliefs through four principal sources: performance accomplishments, vicarious experiences, verbal persuasion, and the interpretation of physiological states. Performance accomplishments play a major role in developing one's efficacy beliefs because they are based on personal mastery experiences and formed by successes, which in turn have been attributed as internal and stable. In the context of TSE, mastery experiences occur with successful teaching. Thus, they contribute to the expectation that future teaching performance will be successful. This formation process is especially relevant in an early career; however, research has shown that the relationship between years of experience and TSE is nonlinear (Klassen and 
Chiu, 2010), rising between zero and 25 years of experience and declining during the last career stage.

Teachers with a high sense of self-efficacy show greater enthusiasm toward teaching (Allinder, 1994), superior teaching performance (Klassen and Tze, 2014), and higher instructional quality (Holzberger et al., 2013). Recently, Zee and Koomen (2016) have reviewed relevant relationships with TSE.

In the past, TSE has been known as an elusive construct (Tschannen-Moran and Woolfolk Hoy, 2001). However, since about 20 years, there is an agreement on TSE's structure: It can be divided into three subcomponents: instructional strategies, classroom management, and student engagement (TschannenMoran and Woolfolk Hoy, 2001). These components have underlined Bandura's formulated need to assess certain levels of specificity in self-efficacy (Bandura, 2006).

Bandura further described the domain specificity of TSE: Teachers can perceive themselves as very effective in teaching, in general, but feel less effective when applying specific teaching practices (Bandura, 2006). Accordingly, adapted measurements for TSE in specific contexts have been developed: for example, inclusive teaching (e.g., Sharma et al., 2012) or implementing selfregulated learning strategies (De Smul et al., 2018). Accordingly, TSE in the context of digital media is also a specific form of TSE. For the purpose of this study, we implanted this specific form of TSE as well as the general form of TSE.

\section{Interplay of TSE and Burnout}

In light of the JD-R model of burnout, much research has determined potential burnout predictors, especially in terms of resources of burnout (e.g., Pas et al., 2012). Particularly, researchers have focused on the reciprocal relationship between burnout and TSE (e.g., Brouwers and Tomic, 2000). Some authors have claimed that TSE is a protective resource when it comes to burnout (Dicke et al., 2015) and research has shown that TSE has a buffering effect when it comes to stress (Bakker et al., 2005). Despite the significant research interest in the relationship between TSE and burnout, studies referring to longitudinal changes in both constructs and their interrelations are relatively old (Brouwers and Tomic, 2000), refer to students (Fives et al., 2007), or novice teachers (Dicke et al., 2015). Moreover, no study has investigated the changes and interrelations of burnout and TSE during the COVID-19 pandemic.

\section{Consequences of the COVID-19 Pandemic}

Previous research has shown that teachers often feel overstrained from responding to their students' emotional needs, especially after catastrophic events (Pfefferbaum et al., 2004). Moreover, it has been documented that after a crisis, symptoms of posttraumatic stress disorder are significantly higher in teacher samples than in the general population (Zhang et al., 2016). Thus, teachers seem vulnerable to psychological stress, which can lead to emotional exhaustion. Müller and Goldenberg (2020) explained that "in addition to processing their own stress, they are also supporting students through theirs" (p. 29) especially considering that some students have little support at home. This emotional workload could very likely lead to depersonalization, which in turn would have deleterious effects on the students in such a situation. In light of this background, more research is needed to investigate the effectson emotional exhaustion, depersonalization as well as lack of accomplishment in teachers, in the context of crises. Considering the present COVID-19 pandemic, another aspect that is possibly stressful for teachers is their high risk of infections at school due to the virus's human-to-human transmission.

In May 2020, schools in Germany were gradually reopened. However, before schools could reopen, teachers had to spontaneously switch to digital learning material-whether prepared or not-in order to teach students from a distance. This switch noticeably changed daily work routines, especially of those with limited experience in digital learning environments. Consequently, considering the JD-R model of burnout, implementing distance learning was possibly related to a stress reaction (emotional exhaustion), which, in turn, could have led to feelings of depersonalization and a lack of accomplishment. These feelings could emerge if TSE was low-especially if teachers felt inadequate in implementing digital learning material or had negative attitudes toward its use.

Research based on the 'Integrative Model of Behavior Prediction to explain teachers' willingness to use Information and Communication Technologies' (Kreijns et al., 2013) has shown that the intention to use digital learning materials for teaching is mainly influenced by teachers' attitudes (Liaw, 2007) and their specific self-efficacy (Van Acker et al., 2013)The latter, thus TSE for the use of digital learning material, can be understood as a context-specific form of TSE and comprises the teachers' belief in their capability to implement digital learning material. Empirical studies have outlined its relevance with findings suggesting that TSE for the use of digital media is a significant predictor for the actual implementation in class (e.g., Kreijns et al., 2013; Lee and Lee, 2014) as well as for a teachers' competence (e.g., López-Vargas et al., 2017). The other important predictor for the intention as well as actual use of digital media are teachers' attitudes toward e-Learning (e.g., Scherer, 2018), thus whether teachers are generally more or less favorable toward e-Learning. Due to the sudden change to distance learning where digital media played a crucial role, we argue that TSE for the use of digital media as well as attitudes toward e-Learning played an important role in explaining changes in teachers' mental health during the COVID-19 pandemic. Both variables could have contributed to changes in burnout whereby teachers feeling less efficacious and having rather negative attitudes could have felt more stressed and overcharged. At the same time, high TSE for e-Learning and positive attitudes could have contributed to general TSE and less burnout in times of the pandemic. As far as we know, no study has investigated these relationships until now. We therefore analyzed in an explorative way if changes in TSE and burnout were related to attitudes or TSE for e-Learning.

Moreover, we controlled for gender and teaching experience in our analyses because both could have had a significant impact on the changes in burnout. Findings regarding gender in the context of burnout are still inconclusive and assume that they depend greatly on the specific burnout component (Lau et al., 2005; Grayson and Alvarez, 2008; Fernet et al., 2012). However, with 
regard to using digital media, male teachers seem to be better prepared (e.g., Gebhardt et al., 2019) and this could have significantly affected the job demand 'distance teaching' and consequently the changes in burnout. Regarding teaching experience and its relation to burnout, findings are rather unclear as well with studies reporting higher burnout rates in more experienced and older teachers (e.g., Klusmann et al., 2008) and others in the opposite (e.g., Lau et al., 2005; Antoniou et al., 2006) but here again, we assume that teaching experience could have affected changes in burnout through teachers' readiness for teaching with digital media. As we wanted to control for such possible effects, we included gender as well as teaching experience as covariates.

\section{Purpose of Our Study}

The purpose of our study is twofold: First, we investigate burnout changes in teachers from the pre- to post-COVID19 outbreak as an indicator of mental health and its relation to changes in (general) TSE as a relevant resource against burnout. Hereby, we claim that the circumstances of the pandemic are a high job demand which would very likely lead to an increase in burnout symptoms (Demerouti et al., 2001). Second, we analyze if those changes are related to specific self-efficacy for using digital media and attitudes toward e-Learning.

1) Hypothesis 1: Burnout symptoms increase from the pre(Timepoint 1 ; t1) to post- (Timepoint 2; t2) COVID-19 outbreak

2) Hypothesis 2: Changes in burnout are negatively related to changes in TSE (Dicke et al., 2015).

3) Hypothesis 3: Changes in burnout from $t 1$ to $t 2$ are related to

a. lower specific TSE for using digital media.

b. negative attitudes toward e-Learning.

4) Hypothesis 4: Changes in general TSE from t1 to t2 are related to

a. higher specific TSE for using digital media.

b. positive attitudes toward e-Learning.

\section{MATERIALS AND METHODS}

This study was conducted in accordance with the ethical standards of the Ethics Committee of the Faculty for Empirical Human Sciences and Economical Sciences (Saarland University) and the data protection committee of the Ministry of Education in Saarland. The participants provided their written informed consent to participate in this study.

\section{Sample and Procedure}

Our sample consisted of 92 teachers from 23 primary and secondary schools $(41.50 \%$ were from secondary schools) working in southwestern Germany. The teachers' ages ranged from 26 to $64(M=40.19, S D=9.63)$, and the mean teaching experience was $M=10.78(S D=8.25)$. Moreover, $82 \%$ of our teacher sample were female. Gender and teaching experience were included as covariates in our analyses.
Links to an online questionnaire, which was designed in Questback's online survey platform, Unipark, were sent twice during the 2019-2020 school year. Participation was voluntary, and teachers were required to provide informed consent before they completed the questionnaires. The first data collection occurred during the beginning of the school year (October-December 2019)_just before the COVID-19 outbreak. The second data collection started in mid-May 2020. The design of the study with its measurement time points had been planned before the outbreak of the pandemic. Initially, the research aim was to capture changes in TSE and burnout to learn more about their development and reciprocity. However, the pandemic provided an interesting opportunity to investigate this research question under unique circumstances.

\section{Instruments}

Response scales for all instruments ranged from 1) don't agree at all to 6) agree entirely. Means were computed for all (sub-)scales. Reliability was determined in terms of internal consistency (Cronbach's $a$ ).

To assess burnout in its multidimensionality, we used the wellestablished Maslach burnout inventory (MBI) by Maslach et al. (1986) in its translated version (Enzmann and Kleiber, 1989). The three scales consisted of emotional exhaustion (e.g., "My work frustrates me," 9 items, $\alpha_{\mathrm{T} 1}=0.86 ; \alpha_{\mathrm{T} 2}=0.88$ ); depersonalization (e.g., "I think I treat some students to some extent impersonally," 5 items, $\alpha_{\mathrm{T} 1}=0.73 ; \alpha_{\mathrm{T} 2}=0.68$ ); and lack of accomplishment (e.g., "I succeed well in putting myself in the position of my students," 8 items, $\alpha_{\mathrm{T} 1}=0.83 ; \alpha_{\mathrm{T} 2}=0.73$ ). The latter is inversely coded and was therefore recoded for better interpretability.

TSE was assessed using Pfitzner-Eden et al. (2014) scale for teacher self-efficacy (STSE) with three dimensions: classroom management (e.g., "I manage to control disruptive behaviour in class," 4 items, $\alpha_{\mathrm{T} 1}=0.88 ; \alpha_{\mathrm{T} 2}=0.86$ ); instructional strategies (e.g., "I am able to provide an alternative explanation or another example when students are confused," 4 items, $\alpha_{\mathrm{T} 1}=0.65 ; \alpha_{\mathrm{T} 2}=$ 0.66 ); and student engagement (e.g., "I can motivate students who have little interest in education," 4 items, $\alpha_{\mathrm{T} 1}=0.83 ; \alpha_{\mathrm{T} 2}=0.77$ ).

In order to assess TSE for using digital media, we used a 4 -item measure (e.g., "I know that I can easily create digital learning environments"). Internal consistency was sufficient ( $\alpha=0.87)$.

Attitudes toward e-Learning were assessed by a translated version of Panda and Mishra (2007) 11-item scale (e.g., "eLearning can solve many of our educational problems," $\alpha=0.92$ ).

\section{Data Analysis}

We conducted the analysis of our hypotheses with $\mathrm{R}$ ( $\mathrm{R}$ Core Team, 2020) using the lavaan package (Rosseel, 2012) with maximum likelihood estimation. The approach of latent change score models (LCSM; McArdle and Nesselroade, 1994) consists of modeling between-person differences in withinperson changes (McArdle, 2009). For this purpose, change is measured by means of a latent difference score that basically represents the difference between two time points. A further extension to the basic LCSM is latent change regression models (LCRM), where the difference score is measured base-free; that is, the difference score is regressed on the Timepoint 1 measurement 


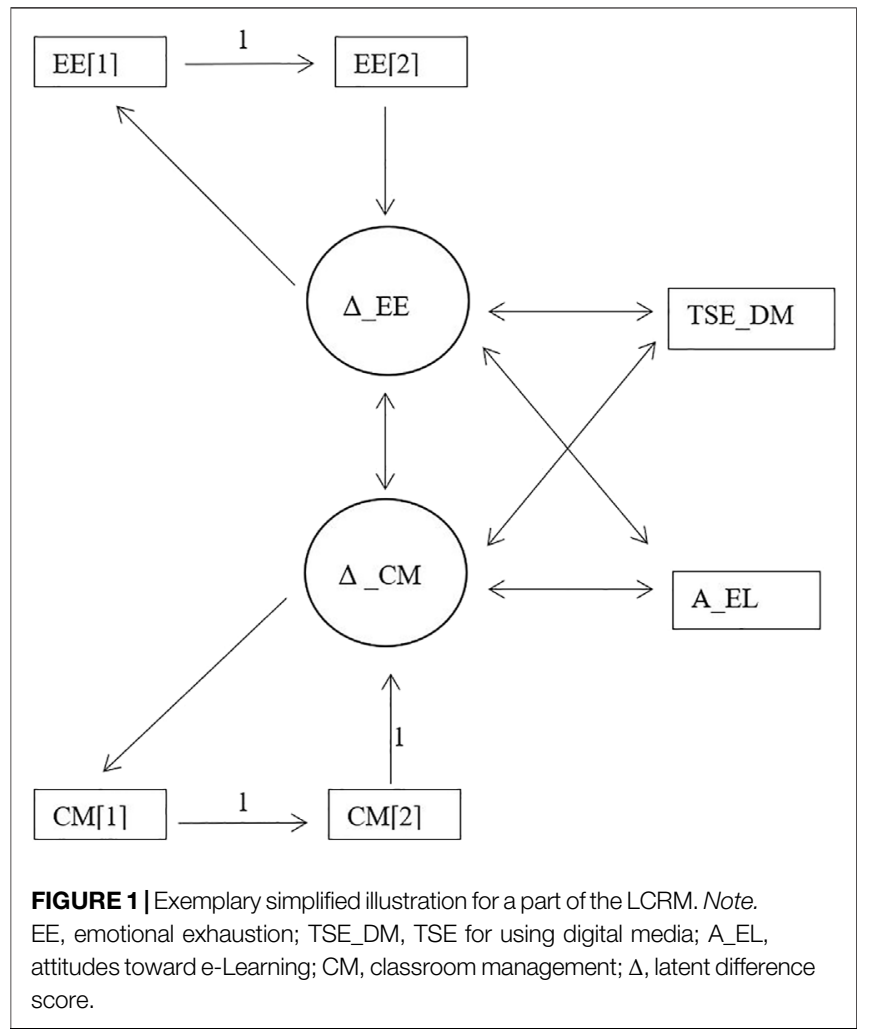

(McArdle, 2009). The mean difference score can then be interpreted as a mean change corrected for Timepoint 1 . LCRM is particularly recommended when the change due to a particular event between two measurement time points is to be measured rather than an ongoing process.

For our analyses, we used an LCRM to model the changes of burnout and TSE over time to investigate the relations in change (Hypotheses $1+2$ ). Moreover, we introduced TSE for e-Learning and attitudes toward e-Learning to investigate their relations to the latent difference variables of the MBI and TSE subscales (Hypotheses $3+4)$. All scales, subscales, and difference scores were allowed to be correlated, resulting in a saturated model $(d f=0)$. Figure 1 shows a simplified LCRM for the subscales of emotional exhaustion (burnout) and classroom management (TSE).

In order to analyze the power for each hypothesis, we conducted a Monte Carlo study with 10,000 replications based on our LCRM results (Zhang and Liu, 2019). The number of repetitions for which the null hypothesis is rejected $(\alpha<0.05)$ can then be interpreted as the power. We refer to the details of the power next to the related results. We consider a power of at least 0.5 as sufficient and values greater than 0.8 as optimal (see Kyriazos, 2018).

\section{RESULTS}

Before answering the hypotheses in the following sections, we provide an overview of means and variances for all variables of the LCRM (Table 1). Please note that differences in means are not comparable to the within-person changes as modeled in the LCRM.
TABLE 1 | Means (M) and standard deviations (SD) of all variables.

\begin{tabular}{lcccc}
\hline & $\boldsymbol{M}_{\boldsymbol{t 1}}$ & $\boldsymbol{S D}_{\boldsymbol{t 1}}$ & $\boldsymbol{M}_{\boldsymbol{t} \mathbf{2}}$ & $\mathbf{S D}_{\boldsymbol{t} \mathbf{2}}$ \\
\hline MBI_EE & 2.94 & 0.96 & 2.48 & 0.91 \\
MBI_LA & 2.31 & 0.66 & 2.14 & 0.51 \\
MBI_DP & 1.90 & 0.87 & 1.81 & 0.75 \\
TSE_CM & 4.73 & 0.91 & 4.88 & 0.71 \\
TSE_SE & 4.64 & 0.74 & 4.70 & 0.65 \\
TSE_IS & 4.96 & 0.62 & 5.05 & 0.55 \\
TSE_DM & - & - & 4.21 & 1.10 \\
A_EL & - & - & 3.27 & 1.07
\end{tabular}

Note. EE, emotional exhaustion; LA, lack of accomplishment; DP, depersonalization; $C M$, classroom management; SE, student engagement; IS, instructional strategies; TSE_DM, TSE for using digital media; A_EL, attitudes toward e-Learning.

TABLE 2 | Correlations of the difference scores for the MBI and TSE subscales.

\begin{tabular}{|c|c|c|c|c|c|}
\hline & $\Delta \_$LA & $\Delta \_$DP & $\Delta_{-} \mathrm{CM}$ & $\Delta \_$SE & $\Delta \_$IS \\
\hline$\Delta \_E E$ & $0.49^{\star \star \star}$ & $0.23^{\star}$ & $-0.40^{\star \star \star}$ & $-0.21^{a}$ & $-0.40^{\star \star \star}$ \\
\hline Power & 0.99 & 0.57 & 0.88 & 0.33 & 0.99 \\
\hline$\Delta \_L A$ & & $0.26^{*}$ & $-0.42^{\star \star \star}$ & $-0.31^{\star \star}$ & $-0.40^{\star \star \star}$ \\
\hline Power & & 0.92 & 0.65 & 0.25 & 0.92 \\
\hline$\Delta \_\mathrm{DP}$ & & & -0.17 & -0.17 & $-0.26^{\star}$ \\
\hline Power & & & 0.07 & 0.29 & 0.50 \\
\hline$\Delta \_C M$ & & & & $0.46^{\star \star \star}$ & $0.48^{\star \star \star}$ \\
\hline Power & & & & 0.83 & 0.81 \\
\hline$\Delta \_S E$ & & & & & $0.56^{\star \star \star}$ \\
\hline Power & & & & & 0.99 \\
\hline
\end{tabular}

Note. $\Delta$, latent difference score; EE, emotional exhaustion; $L A$, lack of accomplishment; $D P$, depersonalization; CM, classroom management; SE, student engagement; IS, instructional strategies.

${ }^{a}<.10, p^{*}<.05, p^{* *}<.01, p^{* * *}<.001$

TABLE 3 | Results of the LCRM for TSE.

\begin{tabular}{lccc}
\hline & $\boldsymbol{M}$ & SE & Power \\
\hline$\Delta_{\text {_CM }}$ & $2.49^{\star \star \star}$ & 0.41 & 0.99 \\
$\Delta_{\text {SE }}$ & $2.31^{\star \star \star}$ & 0.49 & 0.98 \\
$\Delta_{\text {_IS }}$ & $2.04^{\star \star \star}$ & 0.36 & 0.99
\end{tabular}

Note. $\Delta$ = latent difference score, CM, classroom management, SE, student engagement, IS, instructional strategies. $p^{\star * *}<0.001$.

\section{Hypothesis 1}

Following our first hypothesis, we expected all burnout subscales to increase from $\mathrm{t} 1$ (pre-outbreak) to $\mathrm{t} 2$ (post-outbreak). In line with our hypothesis, we found the means of the difference scores for the subscale, lack of accomplishment $(M=0.53, S E=0.16, p<$ 0.001 , Power $=0.97)$ as well as depersonalization $(M=0.94, S E=$ $0.26, p<0.001$, Power $=0.99$ ) to be significant. However, the mean difference score for emotional exhaustion does not indicate a change $(M=-0.24, S E=0.26, p=0.357$, Power $=0.11)$.

\section{Hypothesis 2}

For the purpose of Hypothesis 2, we looked at the latent difference scores, which indicate a change in terms of an increase or decrease and conducted correlations of the difference scores. Results are depicted in Table 2. All subscales 
TABLE 4 | Correlations of the difference scores and related variables.

\begin{tabular}{lcccccc}
\hline & $\boldsymbol{\Delta}_{-}$EE & $\boldsymbol{\Delta}_{-} \mathbf{D P}$ & $\boldsymbol{\Delta}_{-}$LA & $\boldsymbol{\Delta}_{-} \mathbf{C M}$ & $\boldsymbol{\Delta}_{-} \mathbf{S E}$ & $\boldsymbol{\Delta}_{-}$IS \\
\hline TSE_DM & -0.04 & -0.05 & -0.17 & $0.28^{*}$ & 0.11 & 0.17 \\
Power & 0.08 & 0.51 & 0.06 & 0.72 & 0.07 & 0.06 \\
A_EL & -0.02 & 0.02 & 0.04 & 0.00 & 0.03 & 0.09 \\
Power & 0.05 & 0.23 & 0.09 & 0.06 & 0.08 & 0.05 \\
\hline
\end{tabular}

*Note. EE, emotional exhaustion, $L A$ = lack of accomplishment, DP, depersonalization, $C M$, classroom management, SE, student engagement, IS, instructional strategies,

TSE_DM = TSE for using digital media, A_EL, attitudes toward e-Learning. $p<0.05$.

of the MBI are negatively and almost always significantly correlated to the TSE subscales: An increase in MBI subscales is related to less increase in TSE subscales (for changes in TSE subscales, see Table 3). Moreover, changes in the MBI subscales and the TSE subscales are positively related to each other. The standardized coefficient $r$ can be interpreted as the effect size (Durlak, 2009).

Furthermore, we looked at the relations between the change scores and the covariates in an explorative way and found one positive significant relationship between the mean difference score for lack of accomplishment and teaching experience $(\beta=$ $0.23, p<0.01$, Power $=0.97)$. The more experienced the teacher, the more increase in 'lack of accomplishment' they felt.

\section{Hypotheses 3 and 4}

5 In order to answer Hypotheses 3 and 4, we analyzed the correlations of the difference scores with variables from t2-TSE for e-Learning, as well as attitudes toward e-Learning (see Table 4). For TSE for using digital media, we found a significant positive correlation with the change in classroom management: the more self-efficacious teachers feel concerning e-Learning, the more increase in classroom management. The standardized coefficient $r$ can be interpreted as effect size (Durlak, 2009). Attitudes toward e-Learning are not related to the difference scores.

\section{DISCUSSION}

To the best of our knowledge, this was the first study to investigate changes in burnout and TSE by means of LCRM in a sample of inservice teachers. In particular, it is one of the first studies considering mental health changes due to the COVID-19 pandemic together with related constructs (see also e.g.,Sokal et al., 2020a; Kim et al., 2021). Thus, this study deals with a critically important topic.

Applying an LCRM, we found that symptoms of depersonalization, as well as feelings of inefficacy (lack of accomplishment) in teachers, significantly increased from the pre- to post-COVID-19 outbreak which is in line with findings from other studies during the pandemic, e.g., where sample means were compared in two measurement time points within the first 3 months of the pandemic (Sokal et al., 2020b) (see also (Kim et al., 2021). However, emotional exhaustion did not show a significant change in our sample. This finding does not align with the JD-R model of burnout, which postulated that emotional exhaustion develops prior to depersonalization and lack of accomplishment. Nevertheless, considering that emotional exhaustion is instead a consequence of work overload, we contend it was not the quantity of work overload per se that affected teachers' mental health during the COVID-19 pandemic, but the amount of emotional workload (e.g., support of students) could have contributed to teachers' depersonalization as a way to cope with these demands. This is in line with findings from an study in England where teachers were interviewed about their experiences in the first weeks of the pandemic: here three the most relevant themes, that were mentioned by the teachers, were the feeling of uncertainty, "finding a way" to cope with the new situation as well as concerns for vulnerable pupils (Kim and Asbury, 2020). Moreover, the increased feelings of inefficacy seem to have developed due to a lack of resources: i.e., insufficient information or tools to do the job (Maslach, 2003). This result is understandable, considering that teachers had to switch to distance learning overnight.

Moreover, our findings show that changes in accomplishment are highly related to changes in all three STSE subscales, as all STSE subscales significantly increased from $t 1$ to $t 2$. The negative relation of changes means that teachers with less change (increase) in lack of accomplishment show a greater change (increase) in TSE. Strong relations of TSE and accomplishment are a well-known finding, and reduced accomplishment is sometimes described as a negative equivalent to self-efficacy (Lee and Ashforth, 1990). For emotional exhaustion, correlations of change are very similar to those in accomplishment. However, for depersonalization, correlations of change are remarkably smaller, which is consistent with prior research (Brouwers and Tomic, 2000).

Although it was not part of our hypotheses, we briefly address the significant increase in TSE, which may appear surprising. The items of the STSE refer to regular teaching (in classroom) and not to distance learning (online), so we assume that the response tendencies were partly distorted by the different setting and possibly led to overestimations. Additionally, the positive effect could have occurred due to positive mastery experiences (Bandura, 1977) with distance learning and with reduced class sizes (a hygiene measure) when schools reopened.

Furthermore, we analyzed if changes in TSE and burnout were related to attitudes toward e-Learning and self-efficacy for using digital media. Regarding the latter, we found a significant positive relationship with an increase in classroom management. Teachers with higher TSE for using digital media had higher increases in classroom management. If we imagine a teacher with little TSE for using digital mediathe relation with classroom management is understandable if one considers that classroom management for distance learning might have been easier and that back in school, there were smaller classes without interactive methods that were easier to handle. Nevertheless, we found little evidence that changes in burnout and TSE, in general, were related to TSE for using digital media. For attitudes toward e-Learning, we found no evidence at all. Considering the descriptives in Table 1, we have seen that both scales have high standard deviations relative to their mean, which indicate much variance within the sample. The missing relations suggest 
there must be other reasons for increases in burnout, which should be addressed. Moreover, the power for these analyzes was minimal, which implies that significant effects were hard to detect.

Additionally, we had two covariates included in our model: gender and teaching experience. In an explorative way, we looked at the relations with the other variables in the model but found only one significant relation between teaching experience and the change score for lack of accomplishment: more experienced teachers had a higher increase in this component. This finding is understandable in light of previous research that has shown that younger teachers are more confident with respect to the use of digital media (e.g., Eickelmann and Vennemann, 2017; Tondeur et al., 2018). Consequently, those teachers struggle less and are less likely to feel a lack of accomplishment. However, with regard to gender, we did not find any significant relations to other variables which tells us that the development of burnout and TSE in times of the pandemic was independent of the teachers' gender.

\section{Limitations}

The predominant low power is one of our study's main limitations. Furthermore, there are some limits to the interpretation of the results, which generally concern our sample and the associated generalizability of our findings. Teachers took part in our study voluntarily, which could have resulted in a selective sample of teachers willing to provide very personal information.

Our sample mainly consisted of teachers working in southwestern Germany, as well as female teachers (82\%). Regarding the latter, research in gender effects in teacher burnout is still inconclusive (e.g., Timms et al., 2006). Thus, we cannot estimate to what extent our mainly female sample has contributed to our results.

Furthermore, the interpretation of our results is limited by the fact that we know relatively little about what the teachers did between $\mathrm{t} 1$ and $\mathrm{t} 2$ - whether or how they taught online and what their situations were at home. Additionally, when we collected the data for $\mathrm{t} 2$, teachers were just about to return to school. Thus, we were able to capture short-term effects in mental health but further data a few weeks or months later would have given insight into long-term effects. The question whether these effects are remaining, cannot be answered.

\section{Implications for Research and Practice}

Despite these limitations, we have significantly contributed to the research and practice with this study by investigating systematic interrelations in the change of burnout and TSE, which have hardly been investigated thus far. Moreover, this is one of the first studies to analyze teachers' mental health during the COVID-19 pandemic (see also e.g., Sokal et al., 2020a; Kim et al., 2021). A further and particularly important strength lies in the application of latent change score regression modeling, which allowed us to model the relations of change with other variables.
Future research should investigate the interrelation of TSE and burnout in longitudinal designs with more time points and different cohorts to gain insight into whether TSE and burnout development, as well as their interrelations, change over different phases of the professional career. Thus far, only a few studies have investigated Bandura (1977) sources for TSE, and those have focused on teacher practicum or preservice teachers (e.g., Pfitzner-Eden, 2016). However, we still do not know what happens during teachers' professional careers and whether Bandura's sources can predict those changes.

Furthermore, findings must be replicated in different cultures and with samples consisting of a balanced gender ratio to generalize findings. Of further interest would be the closer examination of intraindividual differences, especially in selfefficacy and attitudes toward e-Learning considering the COVID-19 pandemic.

Concerning the specific context of the pandemic, future studies could focus more closely on what exactly contributes to teachers' higher burdens in terms of specific job demands; the findings could help identify the best possible support for teachers. This avenue is also relevant for political decisions, as this pandemic may not be the last. The different development of burnout subscales indicates that the problem was probably not due to work overload but rather to a lack of preparation and information. Finally, the question remains of how the pandemic and the additional burden placed on teachers have affected students.

\section{DATA AVAILABILITY STATEMENT}

The raw data supporting the conclusion of this article will be made available by the authors, without undue reservation.

\section{ETHICS STATEMENT}

The studies involving human participants were reviewed and approved by Ethics Committee of the Faculty for Empirical Human Sciences and Economical Sciences (Saarland University). The patients/participants provided their written informed consent to participate in this study.

\section{AUTHOR CONTRIBUTIONS}

MW designed the study and collected the data. MW and EK analyzed the data. MW wrote the first draft of the article. EK and FP critically reviewed the article. FP supervised the project.

\section{FUNDING}

This work was supported by the Ministry of Education in Saarland, Germany. 


\section{REFERENCES}

Alarcon, G. M. (2011). A Meta-Analysis of Burnout with Job Demands, Resources, and Attitudes. J. Vocational Behav. 79 (2), 549-562. doi:10.1016/ j.jvb.2011.03.007

Allen, R., Jerrim, J., and Sims, S. (2020). How Did the Early Stages of the COVID-19 Pandemic Affect Teacher Wellbeing? CEPEO Working Paper No. 20-15. Centre for Education Policy and Equalising Opportunities, UCL. Available at: https:// EconPapers.repec.org/RePEc:ucl:cepeow:20-15 (Accessed November 9, 2021).

Allinder, R. M. (1994). The Relationship between Efficacy and the Instructional Practices of Special Education Teachers and Consultants. Teach. Educ. Spec. Educ. 17 (2), 86-95. doi:10.1177/088840649401700203

Antoniou, A. S., Polychroni, F., and Vlachakis, A. N. (2006). Gender and Age Differences in Occupational Stress and Professional Burnout between Primary and High-school Teachers in Greece. J. Managerial Psych 21 (7), 682-690. doi:10.1108/02683940610690213

Bakker, A. B., Demerouti, E., and Euwema, M. C. (2005). Job Resources Buffer the Impact of Job Demands on Burnout. J. Occup. Health Psychol. 10 (2), 170-180. doi:10.1037/1076-8998.10.2.170

Bandura, A. (2001). Social Cognitive Theory: An Agentic Perspective. Annu. Rev. Psychol. 52, 1-26. doi:10.1146/annurev.psych.52.1.1

Bandura, A. (2006). "Guide for Constructing Self-Efficacy Scales," in Self-efficacy Beliefs of Adolescents. Editors T. Urdan. and F. Pajares (Charlotte, NC: Information Age Publishing), 307-337. doi:10.1080/09243453.2012.680892

Bandura, A. (1977). Self-Efficacy: Toward a Unifying. Psychol. Rev. 84 (2), 191-215.

Bandura, A. (1986). Social Foundations of Theory of Behavioral Change. Psychol. Rev. 84 (2), 191-215. doi:10.1037/0033-295X.84.2.191

Brouwers, A., and Tomic, W. (2000). A Longitudinal Study of Teacher Burnout and Perceived Self-Efficacy in Classroom Management. Teach. Teach. Educ. 16 (2), 239-253. doi:10.1016/S0742-051X(99)00057-8

De Smul, M., Heirweg, S., Van Keer, H., Devos, G., and Vandevelde, S. (2018). How Competent Do Teachers Feel Instructing Self-Regulated Learning Strategies? Development and Validation of the Teacher Self-Efficacy Scale to Implement SelfRegulated Learning. Teach. Teach. Educ. 71, 214-225. doi:10.1016/j.tate.2018.01.001

Demerouti, E., Bakker, A. B., Nachreiner, F., and Schaufeli, W. B. (2001). The Job Demands-Resources Model of Burnout. J. Appl. Psychol. 86 (3), 499-512. doi:10.1037/0021-9010.86.3.499

Dicke, T., Parker, P. D., Holzberger, D., Kunina-Habenicht, O., Kunter, M., and Leutner, D. (2015). Beginning Teachers' Efficacy and Emotional Exhaustion: Latent Changes, Reciprocity, and the Influence of Professional Knowledge. Contemp. Educ. Psychol. 41, 62-72. doi:10.1016/j.cedpsych.2014.11.003

Durlak, J. A. (2009). How to Select, Calculate, and Interpret Effect Sizes. J. Pediatr. Psychol. 34 (9), 917-928. doi:10.1093/jpepsy/jsp004

Eickelmann, B., and Vennemann, M. (2017). Teachers' Attitudes and Beliefs Regarding ICT in Teaching and Learning in European Countries. Eur. J. Educ. 16 (6), 733-761. doi:10.1177/1474904117725899

Enzmann, D., and Kleiber, D. (1989). Helfer-Leiden: Streß und Burnout in psychosozialen Berufen. Asanger. Available at: https://www.ssoar.info/ssoar/ handle/document/48022 (Accessed May 5, 2021).

Fernet, C., Guay, F., Senécal, C., and Austin, S. (2012). Predicting Intraindividual Changes in Teacher Burnout: The Role of Perceived School Environment and Motivational Factors. Teach. Teach. Educ. 28 (4), 514-525. doi:10.1016/ j.tate.2011.11.013

Fives, H., Hamman, D., and Olivarez, A. (2007). Does Burnout Begin with StudentTeaching? Analyzing Efficacy, Burnout, and Support during the Student-Teaching Semester. Teach. Teach. Educ. 23 (6), 916-934. doi:10.1016/j.tate.2006.03.013

Freudenberger, H. J. (1975). The Staff Burn-Out Syndrome in Alternative Institutions. Psychotherapy: Theor. Res. Pract. 12 (1), 73-82. doi:10.1037/h0086411

García-Carmona, M., Marín, M. D., and Aguayo, R. (2019). Burnout Syndrome in Secondary School Teachers: A Systematic Review and Meta-Analysis. Soc. Psychol. Educ. 22 (1), 189-208. doi:10.1007/s11218-018-9471-9

Gebhardt, E., Thomson, S., Ainley, J., and Hillman, K. (2019). “Teacher Gender and ICT," in Gender Differences in Computer and Information Literacy: An InDepth Analysis of Data from ICILS. Editors E. Gebhardt, S. Thomson, J. Ainley, and K. Hillman (Basel, Switzerland: Springer International Publishing), 53-68. doi:10.1007/978-3-030-26203-7_5
Grayson, J. L., and Alvarez, H. K. (2008). School Climate Factors Relating to Teacher Burnout: A Mediator Model. Teach. Teach. Educ. 24 (5), 1349-1363. doi:10.1016/j.tate.2007.06.005

Hakanen, J. J., Bakker, A. B., and Schaufeli, W. B. (2006). Burnout and Work Engagement Among Teachers. J. Sch. Psychol. 43 (6), 495-513. doi:10.1016/ j.jsp.2005.11.001

Hansen, J., Klusmann, U., and Hanewinkel, R. (2020). Stimmungsbild: Lehrergesundheit in der Corona-Pandemie. Befragung zur Lehrergesundheit 2020. Kiel: IFT-Nord.

Holzberger, D., Philipp, A., and Kunter, M. (2013). How Teachers' Self-Efficacy Is Related to Instructional Quality: A Longitudinal Analysis. J. Educ. Psychol. 105 (3), 774-786. doi:10.1037/a0032198

Huang, Y., and Zhao, N. (2020). Generalized Anxiety Disorder, Depressive Symptoms and Sleep Quality during COVID-19 Outbreak in China: A Web-Based Cross-Sectional Survey. Psychiatry Res. 288, 112954-112956. doi:10.1016/j.psychres.2020.112954

Kim, L., and Asbury, K. (2020). 'Like a Rug had been Pulled From Under You': The Impact of COVID-19 on Teachers in England During the First Six Weeks of the UK Lockdown. Br. J. Educ. Psychol. 90, 1062-1083. doi:10.1111/bjep.12381

Kim, L. E., Oxley, L., and Asbury, K. (2021). "My Brain Feels like a Browser with 100 Tabs Open": A Longitudinal Study of Teachers' Mental Health and Wellbeing during the COVID-19 Pandemic. Br. J. Educ. Psychol. 1, 1-20. doi:10.1111/bjep.12450

Klassen, R. M., and Chiu, M. M. (2010). Effects on Teachers' Self-Efficacy and Job Satisfaction: Teacher Gender, Years of Experience, and Job Stress. J. Educ. Psychol. 102 (3), 741-756. doi:10.1037/a0019237

Klassen, R. M., and Tze, V. M. C. (2014). Teachers' Self-Efficacy, Personality, and Teaching Effectiveness: A Meta-Analysis. Educ. Res. Rev. 12, 59-76. doi:10.1016/j.edurev.2014.06.001

Klusmann, U., Kunter, M., Trautwein, U., Lüdtke, O., and Baumert, J. (2008). Engagement and Emotional Exhaustion in Teachers: Does the School Context Make a Difference? Appl. Psychol. 57, 127-151. doi:10.1111/j.14640597.2008.00358.x

Kreijns, K., Vermeulen, M., Kirschner, P. A., and Buuren, H. V. (2013). Adopting the Integrative Model of Behaviour Prediction to Explain Teachers' Willingness to Use ICT : a Perspective for Research on Teachers' ICT Usage in Pedagogical Practices. Technol. Pedagogy Educ. 22 (1), 55-71. doi:10.1080/ 1475939X.2012.754371

Kyriazos, T. A. (2018). Applied Psychometrics: Sample Size and Sample Power Considerations in Factor Analysis (EFA, CFA) and SEM in General. Psychology 9, 2207-2230. doi:10.4236/psych.2018.98126

Larsen, A. C., $\mathrm{Pa}^{\circ}$ l, U., and Rønnestad, M. H. (2017). Depersonalization Reconsidered: an Empirical Analysis of the Relation between Depersonalization and Cynicism in an Extended Version of the Maslach Burnout Inventory. Nordic Psychol. 69 (3), 160-176. doi:10.1080/ 19012276.2016.1227939

Lau, P. S., Yuen, M. T., and Chan, R. M. (2005). "Do demographic Characteristics Make a Difference to Burnout Among Hong Kong Secondary School Teachers," in Quality-of-life Research in Chinese, Western and Global Contexts (Dordrecht: Springer), 491-516. doi:10.1007/s11205-004-8033-z

Lee, R. T., and Ashforth, B. E. (1990). On the Meaning of Maslach's Three Dimensions of Burnout. J. Appl. Psychol. 75 (6), 743-747. doi:10.1037/00219010.75.6.743

Lee, Y., and Lee, J. (2014). Enhancing Pre-service Teachers' Self-Efficacy Beliefs for Technology Integration through Lesson Planning Practice. Comput. Educ. 73, 121-128. doi:10.1016/j.compedu.2014.01.001

Liaw, S. (2007). Computers and the Internet as a Job Assisted Tool: Based on the Three-Tier Use Model Approach. Comput. Hum. Behav. 23 (1), 399-414. doi:10.1016/j.chb.2004.10.018

López-Vargas, O., Duarte-Suárez, L., and Ibáñez-Ibáñez, J. (2017). Improving Schools Teacher's Computer Self-Efficacy and its Relationship with Cognitive Style and TPACK. Improving Schools 20 (3), 264-277. doi:10.1177/ 1365480217704263

Maslach, C. (1982). Burnout: The Cost of Caring. Upper Saddle River, NJ: PrenticeHall.

Maslach, C., Jackson, S. E., and Leiter, M. P. (1986). Maslach Burnout Inventory. 3rd ed. Palo Alto, CA: Consulting Psychologists Press. 
Maslach, C., Jackson, S. E., and Schwab, R. L. (1996b). "Maslach Burnout Inventory-Educators Survey (MBI-ES)," in MBI Manual. Editors C. Maslach, S. E. Jackson, and M. P. Leiter. 3rd ed. (Mountain View, CA: Consulting Psychologist Press).

Maslach, C. (2003). Job Burnout: New Directions in Research and Intervention. Curr. Dir. Psychol. Sci. 12 (5), 189-192. doi:10.1111/1467-8721.01258

Maslach, C., Schaufeli, W. B., and Leiter, M. P. (2001). Job Burnout. Annu. Rev. Psychol. 52, 397-422. doi:10.1146/annurev.psych.52.1.397

McArdle, J. J. (2009). Latent Variable Modeling of Differences and Changes with Longitudinal Data. Annu. Rev. Psychol. 60, 577-605. doi:10.1146/ annurev.psych.60.110707.163612

McArdle, J. J., and Nesselroade, J. R. (1994). Structuring Data to Study Development and change. Life-Span Dev. Psychol: Methodological Innovations, 223-267.

Müller, L., and Goldenberg, G. (2020). Education in Times of Crisis: The Potential Implications of School Closures for Teachers and Students: A Review of Research Evidence on School Closures and International Approaches to Education during the COVID-19 Pandemic. London: Chartered College of Teaching.

Panda, S., and Mishra, S. (2007). E-Learning in a Mega Open University: Faculty Attitude, Barriers and Motivators. EMI Educ. Media Int. 44 (4), 323-338. doi:10.1080/09523980701680854

Pas, E. T., Bradshaw, C. P., and Hershfeldt, P. A. (2012). Teacher- and SchoolLevel Predictors of Teacher Efficacy and Burnout: Identifying Potential Areas for Support. J. Sch. Psychol. 50 (1), 129-145. doi:10.1016/ j.jsp.2011.07.003

Pfefferbaum, R. L., Fairbrother, G., Brandt, E. N., Robertson, M. J., Gurwitch, R. H., Stuber, J., et al. (2004). Teachers in the Aftermath of Terrorism: A Case Study of One New York City School. Fam. Community Health 27 (3), 250-259. doi:10.1097/00003727-200407000-00012

Pfitzner-Eden, F., Thiel, F., and Horsley, J. (2014). An Adapted Measure of Teacher Self-Efficacy for Preservice Teachers: Exploring its Validity across Two Countries. Z. für Pädagogische Psychol. 28 (3), 83-92. doi:10.1024/10100652/a000125

Pfitzner-Eden, F. (2016). Why Do I Feel More Confident? Bandura's Sources Predict Preservice Teachers' Latent Changes in Teacher Self-Efficacy. Front. Psychol. 7, 1-16. doi:10.3389/fpsyg.2016.01486

Pogere, E. F., López-Sangil, M. C., García-Senorán, M. M., and Gonzáles, A. (2019). Teachers' Job Stressors and Coping Strategies: Their Structural Relationships with Emotional Exhaustion and Autonomy Support. Teach. Teach. Educ. 85, 269-280. doi:10.1016/j.tate.2019.07.001

R Core Team (2020). R: A Language and Environment for Statistical Computing. Vienna, Austria: R Foundation for Statistical Computing. Available: http:// www.R-project.org/.

Rosseel, Y. (2012). Lavaan: An R Package for Structural Equation Modeling. J. Stat. Softw. 48 (2), 1-36. doi:10.18637/jss.v048.i02

Saha, S., and Dutta, T. (2020). A Study on the Psychological Crisis during the Lockdown Caused Due to COVID-19 Pandemic. Afr. J. Biol. Med. Res. 3 (2), 41-49.

Scherer, R. (2018). The Importance of Attitudes toward Technology for Pre-service Teachers' Technological, Pedagogical, and Content Knowledge: Comparing Structural Equation Modelling Approaches. Comput. Hum. Behav. 80, 67-80. doi:10.1016/j.chb.2017.11.003

Sharma, U., Loreman, T., and Forlin, C. (2012). Measuring Teacher Efficacy to Implement Inclusive Practices. J. Res. Spec. Educ. Needs 12 (1), 12-21. doi:10.1111/j.1471-3802.2011.01200.x

Simbula, S., and Guglielmi, D. (2010). Depersonalization or Cynicism, Efficacy or Inefficacy: what Are the Dimensions of Teacher Burnout? Eur. J. Psychol. Educ. 25 (3), 301-314. doi:10.1007/s10212-010-0017-6

Skaalvik, E. M., and Skaalvik, S. (2017). Motivated for Teaching? Associations with School Goal Structure, Teacher Self-Efficacy, Job Satisfaction and Emotional Exhaustion. Teach. Teach. Educ. 67, 152-160. doi:10.1016/j.tate.2017.06.006
Skaalvik, E. M., and Skaalvik, S. (2011). Teacher Job Satisfaction and Motivation to Leave the Teaching Profession: Relations with School Context, Feeling of Belonging, and Emotional Exhaustion. Teach. Teach. Educ. 27 (6), 1029-1038. doi:10.1016/j.tate.2011.04.001

Sokal, L. J., Trudel, L. E., and Babb, J. (2020a). Canadian Teachers' Attitudes toward Change, Efficacy, and Burnout during the COVID-19 Pandemic. Int. J. Educ. Res. Open 1, 100016. doi:10.1016/j.ijedro.2020.100016

Sokal, L. J., Trudel, L. E., and Babb, J. (2020b). Supporting Teachers in Times of Change: The Job Demands-Resources Model and Teacher Burnout during the COVID-19 Pandemic. Int. J. Contemp. Educ. 3 (2), 67-74. doi:10.11114/ ijce.v3i2.4931

Timms, C., Graham, D., and Caltabiano, M. (2006). Gender Implication of Perceptions of Trustworthiness of School Administration and Teacher Burnout/job Stress. Aust. J. Soc. Issues 41 (3), 343-358. doi:10.1002/j.18394655.2006.tb00020.x

Tondeur, J., Aesaert, K., Prestridge, S., and Consuegra, E. (2018). A Multilevel Analysis of What Matters in the Training of Pre-Service Teacher's ICT Competencies. Comput. Educ. 122, 32-42. doi:10.1016/ j.compedu.2018.03.002

Tschannen-Moran, M., Woolfolk Hoy, A., and Hoy, W. K. (1998). Teacher Efficacy: Its Meaning and Measure. Rev. Educ. Res. 68 (2), 202-248. doi: $10.3102 / 00346543068002202$

Tschannen-Moran, M., and Woolfolk Hoy, A. (2001). Teacher Efficacy: Capturing an Elusive Construct. Teach. Teach. Educ. 17 (7), 783-805. doi:10.1016/S0742051X(01)00036-1

UNESCO (2020). Education: From Disruption to Recovery. Available at: https:// en.unesco.org/covid19/educationresponse (Accessed May 5, 2021).

Van Acker, F., Van Buuren, H., Kreijns, K., and Vermeulen, M. (2013). Why Teachers Use Digital Learning Materials: The Role of Self-Efficacy, Subjective Norm and Attitude. Educ. Inf. Tech. 18, 495-514. doi:10.1007/s10639-0119181-9

Zee, M., and Koomen, H. M. Y. (2016). Teacher Self-Efficacy and its Effects on Classroom Processes, Student Academic Adjustment, and Teacher Well-Being: A Synthesis of 40 Years of Research. Rev. Educ. Res. 86 (4), 981-1015. doi:10.3102/0034654315626801

Zhang, J., Zhang, Y., Du, C., Zhu, S., Huang, Y., Tian, Y., et al. (2016). Prevalence and Risk Factors of Posttraumatic Stress Disorder Among Teachers 3 Months after the Lushan Earthquake: A Cross-Sectional Study. Medicine 95 (29), 1-6. doi:10.1097/MD.0000000000004298

Zhang, Z., and Liu, H. (2019). "Sample Size Planning for Latent Change Score Models through Monte Carlo Simulation," in Longitudinal Multivariate Psychology. Editors E. Ferrer, S. M. Boker, and K. J. Grimm (New York: Taylor \& Francis), 189-211.

Conflict of Interest: The authors declare that the research was conducted in the absence of any commercial or financial relationships that could be construed as a potential conflict of interest.

Publisher's Note: All claims expressed in this article are solely those of the authors and do not necessarily represent those of their affiliated organizations, or those of the publisher, the editors, and the reviewers. Any product that may be evaluated in this article, or claim that may be made by its manufacturer, is not guaranteed or endorsed by the publisher.

Copyright (๑) 2022 Weißenfels, Klopp and Perels. This is an open-access article distributed under the terms of the Creative Commons Attribution License (CC BY). The use, distribution or reproduction in other forums is permitted, provided the original author(s) and the copyright owner(s) are credited and that the original publication in this journal is cited, in accordance with accepted academic practice. No use, distribution or reproduction is permitted which does not comply with these terms. 